\title{
Review Article \\ Endoscopic Treatment of Vesicoureteral Reflux with Dextranomer/Hyaluronic Acid in Children
}

\author{
Wolfgang H. Cerwinka, Hal C. Scherz, and Andrew J. Kirsch \\ Children's Healthcare of Atlanta, Emory University School of Medicine, 5445 Meridian Mark Road, \\ Suite 420, Atlanta, GA 30342, USA \\ Correspondence should be addressed to Wolfgang H. Cerwinka, wcerwin@emory.edu \\ Received 8 January 2008; Accepted 14 May 2008 \\ Recommended by Walid A. Farhat
}

Purpose. The goal of this review is to present current indications, injectable agents, techniques, success rates, complications, and potential future applications of endoscopic treatment for vesicoureteral reflux (VUR) in children. Materials and Methods. The endoscopic method currently achieving one of the highest success rates is the double hydrodistention-implantation technique (HIT). This method employs dextranomer/hyaluronic acid copolymer, which has been used in pediatric urology for over 10 years and may be at present the first choice injectable agent due to its safety and efficacy. Results. While most contemporary series report cure rates of greater than $85 \%$ for primary VUR, success rates of complicated cases of VUR may be, depending on the case, significantly lower. Endoscopic treatment offers major advantages to patients while avoiding potentially complicated open surgery. As the HIT method continues to be applied to complex cases of VUR and more outcome data become available, the indication for endoscopic treatment may exceed the scope of primary VUR. Conclusions. Endoscopic injection is emerging as the treatment of choice for VUR in children.

Copyright (c) 2008 Wolfgang H. Cerwinka et al. This is an open access article distributed under the Creative Commons Attribution License, which permits unrestricted use, distribution, and reproduction in any medium, provided the original work is properly cited.

\section{INTRODUCTION}

Vesicoureteral reflux (VUR) is diagnosed in approximately $1 \%$ of children and promotes pyelonephritis, which may lead to renal scarring and hypertension [1]. VUR is one of many treatable risk factors (e.g., dysfunctional elimination) in the development of urinary tract infection (UTI). Treatment intends to prevent pyelonephritis and to preserve renal function and most children diagnosed with VUR receive antibiotic prophylaxis regardless of VUR grade [2]. Surgical management is indicated in cases of breakthrough UTIs and/or persistence of VUR and comprises ureteral reimplantation and endoscopic injection. Since the introduction of endoscopic treatment for VUR in 1981 and its first clinical application in 1984 as subureteric Teflon injection (STING), injection techniques, injectable agents, and consequently treatment success rates have considerably improved [3-6]. Endoscopic treatment not only approaches success rates of open ureteral reimplantation but offers also significant advantages to patients and parents such as outpatient surgery, lower morbidity (e.g., pain, scar), fewer complications, and reduced cost. Consequently, a major shift from reimplantations toward injection treatments has been observed over the last few years (Figure 1).

The purpose of this review is to summarize current indications, injectable agents, techniques, success rates, complications, and potential future applications of endoscopic treatment for VUR.

\section{MATERIALS AND METHODS}

\subsection{Goals of treatment}

There is little evidence that antireflux surgery of any means decreases the incidence of renal scarring or end-stage renal disease. Worthwhile goals of treatment are to prevent UTIs, particularly febrile UTIs, to avoid long-term antibiotic use, and to lessen the need for distressing voiding cystourethrographies (VCUG) and radiation exposure. Proponents of the endoscopic approach will argue that decreasing the incidence of UTI is the main goal of therapy. Recurrence, while possible, may occur in the absence of symptoms and 


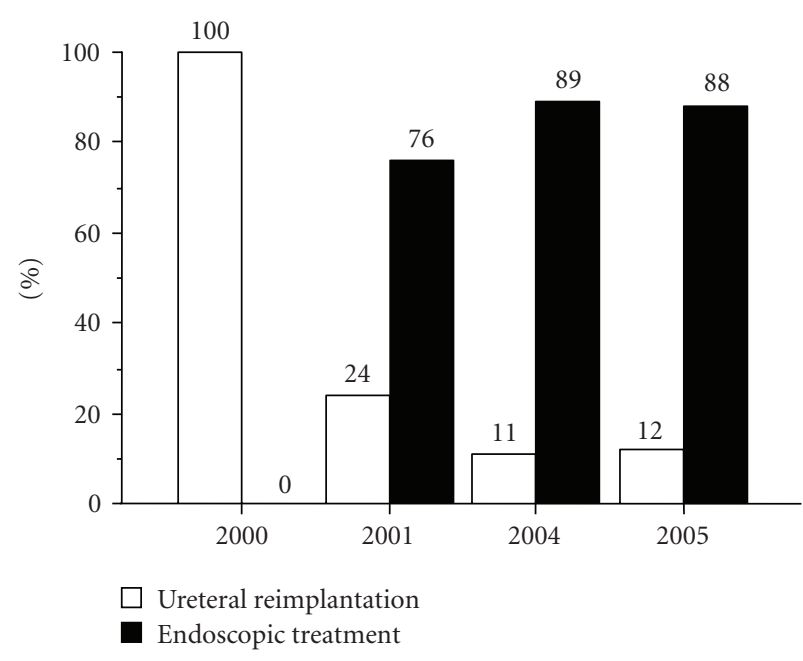

FIgURE 1: Trend of surgical treatment for VUR at Children's Healthcare of Atlanta from 2000 to 2005.

be viewed as subclinical, similar to an individual with VUR diagnosed after a sibling screen or for fetal hydronephrosis. Proponents of the open surgical approach will argue that ureteral reimplantation provides a permanent cure of VUR and is worth the increased morbidity to achieve this goal. In terms of reducing the risk of UTI, endoscopic treatment may achieve this goal as well or better than open surgery [7-9].

\subsection{Indications}

The indications for ureteral reimplantation and endoscopic treatment are with few exceptions identical and comprise recurrent UTIs despite antibiotic prophylaxis, persistent VUR after a period of observation ( $>2$ years), poor compliance with antibiotic prophylaxis, and new renal scarring. When parents are counseled regarding surgical options, a significant preference for endoscopic treatment is apparent $[10,11]$. Endoscopic injection has more frequently been employed for primary rather than for complex VUR (i.e., VUR associated with functional or anatomical abnormalities such as neurogenic bladder or ectopic or megaureters). Avoidance of endoscopic treatment for complex VUR is due to a paucity of supportive clinical data and the current view that bladder dysfunction and structural defects of the ureterovesical junction necessitate ureteral reimplantation. Endoscopic treatment is Food and Drug Administration (FDA)-approved for VUR grades II to IV and for cases of initial endoscopic treatment failure, however it has been applied to all VUR scenarios. While open ureteral reimplantation is the treatment of choice for failed injection therapy, endoscopic treatment has been successfully employed after failed ureteral reimplantation [12-14]. In general, endoscopic treatment is emerging as the treatment modality of choice for VUR whereas ureteral reimplantation remains reserved for cases of failed injection therapy, significant anatomical abnormalities (e.g., large paraureteral diverticula, ectopic ureters, megaureters), and surgeon's or parents' preference.

\subsection{Injectable agents}

Numerous injectable bulking materials have been utilized and abandoned over time in search for the ideal agent, which should be nonimmunogenic, noncarcinogenic, biocompatible, and biodegradable. Teflon, the first bulking material used for the treatment of VUR, was abandoned in pediatric urology in the USA because of the material's propensity to migrate to distant organs and to form granulomas; however, carcinogenesis of Teflon has not been reported [15-17]. Silicone also demonstrates distant migration and granuloma formation. Its carcinogenic potential has been controversial but is most likely unsubstantiated [18, 19]. Glutaraldehyde cross-linked bovine collagen demonstrates a lower degree of absorption as compared to native collagen and can cause allergic reactions even in patients with negative skin test [20]. Several new bulking agents are currently under investigation, such as inorganic materials and autologous tissue. The latter is nonimmunogenic, however, cell harvest and/or cell culture are time-consuming and expensive. Dextranomer/hyaluronic acid copolymer (Deflux, Q-Med Scandinavia Inc., Uppsala, Sweden) is easy to inject, is biodegradable with stable implant volume, and its relatively large particle size prevents distant migration [21, 22]. It has been used as injectable material in pediatric urology for over 10 years and is currently the first-choice injectable agent due to its safety and efficacy. Deflux implants in animal tissue were shown to undergo time-dependent histopathological changes. The initial phase was dominated by an ingrowth of granulation tissue, a foreign-body giant-cell reaction, and the formation of a surrounding capsule. In the later phase, cellular elements were largely replaced by a collagen-rich matrix, whereas the capsule remained unchanged [21]. These findings were confirmed in patients who experienced failed endoscopic injection and proceeded to ureteral reimplantation [22]. In our experience, explanted Deflux appears essentially unchanged up to 4 years after implantation. Besides biological properties, cost of bulking agents, and surgeon's experience, the choice may ultimately depend on approval by administrative agencies, such as the European Medicines Agency or the FDA.

\subsection{Technique}

The endoscopic method currently achieving one of the highest success rates is the double hydrodistention-implantation technique (HIT). Cystoscopy is performed with a pediatric cystoscope equipped with an off-set lens. An off-set lens permits direct passage of the needle in line with the ureter without bending the needle. The bladder is filled to less than half capacity to permit visualization of the ureter and avoid tension within the submucosal layer of the ureter secondary to overdistention. Hydrodistention (HD) is performed with the tip of the cystoscope placed at the ureteral orifice (UO), a pressured stream achieved by placing the irrigation bag approximately 1 meter above the bladder on full flow. HD of the distal ureter serves two purposes: it allows visualization of the intraureteral injection site and assessment of treatment progress (i.e., ureteral coaptation). 
The needle is passed into the UO and inserted at the mid ureteral tunnel at the 6 o'clock position. Sufficient bulking agent is injected to produce a bulge, which initially coapts the detrusor tunnel, while a second implant within the most distal intramural tunnel leads to coaptation of the UO (approximately $1-1.5 \mathrm{~mL}$ ). Rarely, if the two intraureteric submucosal injections (double-HIT method) fail to coapt the ureter, a classic STING or a supraureteric injection is needed to achieve coaptation. The latter two injection sites are used more commonly in complex or redo cases (Figure 2). HD is performed after each injection to monitor treatment progress; when $\mathrm{HD}$ ceases to dilate the UO, appropriate coaptation has been achieved. At our institution, all procedures are performed on an outpatient basis and all patients receive preoperative antibiotic prophylaxis, which is continued until resolution of VUR has been confirmed. Radiographic success is defined as grade 0 VUR on a postoperative VCUG, from 1 to 3 months after a single treatment. Patients are then followed clinically on an annual basis to determine clinical success and recurrence.

We have shown that the Deflux bleb size, determined by ultrasound, correlates with treatment success; a measured volume higher than $25 \%$ of the injected volume using the HIT method will result in a 90\% cure and 95\% using the double HIT method [23, 24]. Consequently, as part of a prospective clinical trial we are evaluating bladder ultrasounds from 4 to 6 weeks after endoscopic injection with measurement of the Deflux bleb. If the retained volume is $>25 \%$, antibiotics will be discontinued, no VCUG will be obtained until 1 year, and the patient will be followed clinically. An earlier VCUG will be obtained for volumes $<25 \%$ or if clinically indicated. This protocol allows for the identification of clinically significant VUR and will evaluate the longer-term success rate. If the long-term VCUGs show favorable results and/or if patients do well clinically, the postoperative VCUG will be excluded in the future.

\section{RESULTS AND DISCUSSION}

\subsection{Success rates}

Outcome of endoscopic treatment for VUR has been evaluated in several large series (Table 1). Most studies included both, primary and complicated cases of VUR. Interpretation of and comparison among these studies are confounded by different inclusion criteria (e.g., with or without complex VUR, grade I, grade V), varying lengths of follow-up, definitions of success, and single versus multiple injections. Nevertheless, most current series report cure rates of greater than $85 \%$. Age, gender, and bilaterality of VUR have not been shown to predict treatment outcome. While the STING technique yields lower success rates with higher grades of VUR, the HIT method achieves similar outcomes across all VUR grades up to grade V [5]. Endoscopic treatment of complicated VUR has been evaluated in smaller series and success rates vary significantly depending on the associated pathologies (Table 2). In general, cure rates for complex cases of VUR are lower than for primary VUR. Treatment of VUR associated with neurogenic bladder was shown

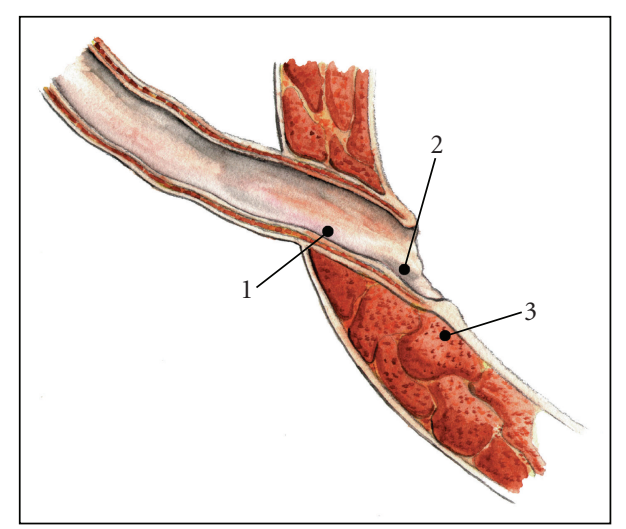

FIGURE 2: Needle placement algorithm for the endoscopic treatment of VUR. Sites 1 and 2 comprise the double-HIT method, while site 3 (STING) is rarely used.

to yield acceptable outcome whereas voiding dysfunction was a significant predictor of treatment failure [13, 25]. Endoscopic injection has been successfully employed in patients who either failed ureteral reimplantation or initial injection $[13,14,26]$. Injection after failed reimplantion or second injection will be curative in most instances whereas a third injection has been shown to be far less successful $[27,28]$. Refluxing ureters of transplanted kidneys in symptomatic patients may be treated endoscopically. Although this approach is curative in only half the cases, yet it represents an attractive alternative to open surgery in the setting of immune compromise and reduced wound healing properties [29]. VUR associated with anatomical abnormalities, previously thought to be contraindications for endoscopic treatment, was recently shown to be amenable to injection treatment [30-32].

There are many factors that may affect the success of the procedure. Preoperative (i.e., patient selection), intraoperative (i.e., injection technique), and postoperative variables have been shown to correlate with treatment outcome (Table 3). Postoperatively, failures may result from Deflux displacement (implant migration), disruption (mucosal breach), or dissolution (decrease in implant volume).

\subsection{Advantages}

In comparison to ureteral reimplantation, endoscopic VUR treatment offers major advantages to patients and parents. The procedure generally lasts less than 15 minutes and is performed on an outpatient basis. While cure rates are approaching those of open ureteral reimplantation, significant complications are rare. Endoscopic treatment entails greater patient convenience, lower morbidity (e.g., pain, abdominal scar), and reduced cost $[43,44]$. Consequently, a significant parental preference for endoscopic treatment is evident $[10,11]$. A recent study demonstrated that both, patients and parents viewed injection therapy as the least bothersome aspect of VUR treatment followed by antibiotic prophylaxis and VCUG [8]. 
TABLE 1: Success rates of endoscopic treatment for primary VUR. Meta-analysis by Elder JS et al. 2006 summarizes results until 2003. More recent series are listed below. Initial success after one treatment and final success after two or more treatments.

\begin{tabular}{|c|c|c|c|c|c|c|}
\hline \multirow{2}{*}{ Reference } & \multirow{2}{*}{ Bulking agent } & \multirow{2}{*}{ Injected volume } & \multirow{2}{*}{ Ureters } & \multirow{2}{*}{ Follow-up } & \multicolumn{2}{|c|}{ Success } \\
\hline & & & & & Initial & Final \\
\hline Elder et al. 2006 [27] & Various & $0.2-1.7 \mathrm{~mL}$ & 8101 & variable & $76 \%$ & $85 \%$ \\
\hline Capozza et al. 2004 [33] & Various & $0.2-2.2 \mathrm{~mL}$ & 1694 & 12-204 months & & $77 \%$ \\
\hline Kirsch et al. 2004 [5] & $\mathrm{Dx} / \mathrm{HA}$ & $0.5-1.5 \mathrm{~mL}$ & 119 & 3-12 months & $92 \%$ & \\
\hline Kirsch et al. 2006 [34] & $\mathrm{Dx} / \mathrm{HA}$ & $0.8-2.0 \mathrm{~mL}$ & 139 & 3-18 months & $93 \%$ & \\
\hline Van Capelle et al. 2004 [35] & PDMS & $0.2-2 \mathrm{~mL}$ & 311 & $3-110$ months & & $75 \%$ \\
\hline Kajbafzadeh et al. 2006 [36] & Ca hydroxylapatite & $0.4-0.6 \mathrm{~mL}$ & 364 & 6 months & & $69 \%$ \\
\hline Yu and Roth 2006 [6] & Dx/HA & $1 \mathrm{~mL}$ & 162 & $2-26$ months & $87 \%$ & $93 \%$ \\
\hline Puri et al. 2006 [37] & Dx/HA & $0.2-1.5 \mathrm{~mL}$ & 1101 & 3-46 months & $87 \%$ & $96 \%$ \\
\hline Lorenzo et al. 2006 [38] & PDMS & & 351 & 72 months & & $72 \%$ \\
\hline Pinto et al. 2006 [39] & $\mathrm{Dx} / \mathrm{HA}$ & & 86 & 3 months & & $84 \%$ \\
\hline
\end{tabular}

TABLE 2: Success rates of endoscopic treatment for complex VUR.

\begin{tabular}{|c|c|c|c|c|c|c|}
\hline Reference & Pathology & Bulking agent & Injected volume & Ureters & Follow-Up & Success \\
\hline Perez-Brayfield et al. 2004 [13] & Neurogenic bladder & Dx/HA & $0.4-2.0(1.1)$ & 9 & 3 months & $78 \%$ \\
\hline Capozza et al. 2002 [25] & Voiding dysfunction & $\mathrm{Dx} / \mathrm{HA}$ & & & 3-6 months & $49 \%$ \\
\hline Elmore et al. 2006 [26] & Failed initial injection & $\mathrm{Dx} / \mathrm{HA}$ & $1.0-1.5$ & 53 & 3 months & $89 \%$ \\
\hline Perez-Brayfield et al. 2004 [13] & Failed reimplantation & $\mathrm{Dx} / \mathrm{HA}$ & $0.4-2.0(1.1)$ & 19 & 3 months & $88 \%$ \\
\hline Kitchens et al. $2006[14]$ & Failed reimplantation & $\mathrm{Dx} / \mathrm{HA}$ & $0.7-3.8(0.8)$ & 20 & 19 months & $83 \%$ \\
\hline Campbell et al. 2006 [29] & Renal transplantation & $\mathrm{Dx} / \mathrm{HA}$ & & 11 & & $55 \%$ \\
\hline Molitierno et al. 2007 [30] & Duplicated ureter & $\mathrm{Dx} / \mathrm{HA}$ & $0.8-2.8(1.4)$ & 63 & $1-3$ months & $85 \%$ \\
\hline Cerwinka et al. 2007 [31] & Paraureteral diverticulum & $\mathrm{Dx} / \mathrm{HA}$ & $0.8-1.8(1.2)$ & 20 & 6.6 months & $81 \%$ \\
\hline Chertin et al. 2007 [32] & Ureterocele & Various & & 44 & $1-21$ months & $91 \%$ \\
\hline
\end{tabular}

\subsection{Complications}

The most common complications following endoscopic treatment of VUR are new contralateral VUR (2.3-17.3\%) and treatment failure $[35,38]$. Less than $4 \%$ of children complain of flank pain or emesis several hours after the procedure and all respond to analgesics [5]. Gross hematuria, urinary retention, or febrile UTIs have not been observed. The most significant potential complication of endoscopic treatment for VUR includes a $0.6 \%$ risk of ureteral obstruction [45]. Our obstruction rate is 4 ureters ( 2 patients) in over 1200 ureteral injections, or $<0.3 \%$. A 7-month old boy with bilateral grade V VUR and spina bifida developed acute renal failure and had bilateral ureteral stents placed. A STING technique using $0.7 \mathrm{~mL}$ was utilized. A postoperative VCUG after stent removal showed bilateral grade V VUR and a vesicostomy was performed. Interestingly, no VUR was seen at the time of bladder augmentation 5 years later. A 6-year old girl developed bilateral ureteral obstruction after HIT using $1.1 \mathrm{~mL}$ and $0.7 \mathrm{~mL}$. Bilateral nephrostomy tubes were placed and removed 6 weeks later after a normal antegrade study. The VCUG did not show any evidence of VUR and no further treatment was required.
Factors that may increase the risk of obstruction include bladder dysfunction and markedly dilated ureters. Patients with recurrent VUR often remain asymptomatic and without risk factors for pyelonephritis such as young age, voiding dysfunction, or significant history of UTIs may be taken off antibiotic prophylaxis [46]. Febrile UTIs after radiographically successful endoscopic treatment warrant evaluation for recurrent VUR.

\subsection{Potential future applications}

As endoscopic treatment continues to be applied to more complex cases of VUR and outcome data become available, the indication for endoscopic treatment may exceed the scope of primary VUR. In the USA, for example, duplex ureters are no longer considered a contraindication for endoscopic treatment with Deflux by the FDA. Outcome analysis of complex cases of VUR will aid in preoperative counseling and patient selection and paired with proper technique further improve success rates of endoscopic VUR treatment. As adults with recurrent pyelonephritis are more consistently evaluated for VUR, a patient population with distinct requirements and disease characteristics may 
TABLE 3: Variables affecting the outcome of endoscopic treatment of VUR with Deflux. Overall success for patients/ureters.

\begin{tabular}{|c|c|c|c|c|c|c|}
\hline Reference & Bulking agent & Patients/Ureters & Mean age & Overall success & Predictors of success & Not predictive \\
\hline \multirow[t]{3}{*}{ Lavelle et al. 2005 [40] } & $\mathrm{Dx} / \mathrm{HA}$ & $52 / 80$ & 7.6 years & $71 \% / 80 \%$ & Volcano: present $87 \%$ & Voiding dysfunction \\
\hline & & & & & absent $53 \%$ & VUR grade \\
\hline & & & & & & Injected volume \\
\hline \multirow[t]{5}{*}{ Yucel et al. 2007 [41] } & $\mathrm{Dx} / \mathrm{HA}$ & $168 / 259$ & 4.2 years & $82 \% / 86 \%$ & Volcano: present $87 \%$ & Voiding dysfunction \\
\hline & & & & & absent $36 \%$ & Laterality \\
\hline & & & & & Volume: $<0.5 \mathrm{~mL}$ success & \\
\hline & & & & & $>0.5 \mathrm{~mL}$ failure & \\
\hline & & & & & VUR grade & \\
\hline \multirow[t]{2}{*}{ Routh et al. 2007 [42] } & $\mathrm{Dx} / \mathrm{HA}$ & $301 / 453$ & 5.5 years & $66 \% / 72 \%$ & VUR grade & \\
\hline & & & & & Surgeon & \\
\hline
\end{tabular}

emerge. Finally, once more accurate predictors of VUR resolution/persistence become available, endoscopic treatment may be more frequently used as the primary treatment in patients with low probability of VUR resolution.

\section{CONCLUSIONS}

Endoscopic treatment of VUR offers significant advantages to patients and avoids potentially complicated open surgery. While success of endoscopic treatment for primary VUR approaches that of ureteral reimplantation, it is acceptable in complex cases of VUR. Consequently, endoscopic injection has assumed the role of first-line VUR treatment whereas ureteral reimplantation remains reserved for cases of failed injection therapy or significant anatomical abnormalities. The development of new injectable agents in combination with the improvement of endoscopic techniques will continue to strengthen the role of endoscopic treatment for VUR.

\section{ABBREVIATIONS}

VUR: Vesicoureteral reflux

UTI: Urinary tract infection

STING: Subureteric Teflon injection

VCUG: Voiding cystourethrography

FDA: Food and Drug Administration

HIT: Hydrodistention Implantation Technique

HD: Hydrodistention

UO: Ureteral orifice.

\section{REFERENCES}

[1] S. H. Jacobson, S. Hansson, and B. Jakobsson, "Vesico-ureteric reflux: occurrence and long-term risks," Acta Paediatrica, vol. 88, supplement 431, pp. 22-30, 1999.

[2] J. S. Elder, C. A. Peters, B. S. Arant Jr., et al., "Pediatric vesicoureteral reflux guidelines panel summary report on the management of primary vesicoureteral reflux in children," The Journal of Urology, vol. 157, no. 5, pp. 1846-1851, 1997.

[3] E. Matouschek, "Die Behandlung des vesikorenalen Refluxes durch transurethrale Einspritzung von Teflonpaste," Der Urologe Ausgabe A, vol. 20, no. 5, pp. 263-264, 1981.
[4] B. O'Donnell and P. Puri, "Treatment of vesicoureteric reflux by endoscopic injection of Teflon," British Medical Journal, vol. 289, no. 6436, pp. 7-9, 1984.

[5] A. J. Kirsch, M. Perez-Brayfield, E. A. Smith, and H. C. Scherz, "The modified sting procedure to correct vesicoureteral reflux: improved results with submucosal implantation within the intramural ureter," The Journal of Urology, vol. 171, no. 6, part 1, pp. 2413-2416, 2004.

[6] R. N. Yu and D. R. Roth, "Treatment of vesicoureteral reflux using endoscopic injection of nonanimal stabilized hyaluronic acid/dextranomer gel: initial experience in pediatric patients by a single surgeon," Pediatrics, vol. 118, no. 2, pp. 698-703, 2006.

[7] U. Jodal, J. M. Smellie, H. Lax, and P. F. Hoyer, "Tenyear results of randomized treatment of children with severe vesicoureteral reflux. Final report of the International Reflux Study in Children," Pediatric Nephrology, vol. 21, no. 6, pp. 785-792, 2006.

[8] A. Stenberg and G. Läckgren, "Treatment of vesicoureteral reflux in children using stabilized non-animal hyaluronic acid/dextranomer gel (NASHA/DX): a long-term observational study," Journal of Pediatric Urology, vol. 3, no. 2, pp. 8085, 2007.

[9] J. M. Elmore, A. J. Kirsch, E. A. Heiss, A. Gilchrist, and H. C. Scherz, "Incidence of urinary tract infections in children after successful ureteral reimplantation versus endoscopic dextranomer/hyaluronic acid implantation," The Journal of Urology, vol. 179, no. 6, pp. 2364-2368, 2008.

[10] K. Ogan, H. G. Pohl, D. Carlson, A. B. Belman, and H. G. Rushton, "Parental preferences in the management of vesicoureteral reflux," The Journal of Urology, vol. 166, no. 1, pp. 240-243, 2001.

[11] N. Capozza, A. Lais, E. Matarazzo, S. Nappo, M. Patricolo, and P. Caione, "Treatment of vesico-ureteric reflux: a new algorithm based on parental preference," BJU International, vol. 92, no. 3, pp. 285-288, 2003.

[12] J. M. Elmore, A. J. Kirsch, M. R. Perez-Brayfield, H. C. Scherz, and M. A. Koyle, "Salvage extravesical ureteral reimplantation after failed endoscopic surgery for vesicoureteral reflux," The Journal of Urology, vol. 176, no. 3, pp. 1158-1160, 2006.

[13] M. Perez-Brayfield, A. J. Kirsch, T. W. Hensle, M. A. Koyle, P. Furness, and H. C. Scherz, "Endoscopic treatment with dextranomer/hyaluronic acid for complex cases of vesicoureteral reflux," The Journal of Urology, vol. 172, no. 4, supplement 1, pp. 1614-1616, 2004. 
[14] D. Kitchens, E. Minevich, W. DeFoor, et al., "Endoscopic injection of dextranomer/hyaluronic acid copolymer to correct vesicoureteral reflux following failed ureteroneocystostomy," The Journal of Urology, vol. 176, no. 4, supplement 1, pp. 1861$1863,2006$.

[15] A. A. Malizia Jr., H. M. Reiman, R. P. Myers, et al., "Migration and granulomatous reaction after periurethral injection of polytef (Teflon)," Journal of the American Medical Association, vol. 251, no. 24, pp. 3277-3281, 1984.

[16] P. A. Dewan, "Is injected polytetrafluoroethylene (Polytef) carcinogenic?” British Journal of Urology, vol. 69, no. 1, pp. 2933, 1992.

[17] I. A. Aaronson, R. A. Rames, W. B. Greene, L. G. Walsh, U. A. Hasal, and P. D. Garen, "Endoscopic treatment of reflux: migration of Teflon to the lungs and brain," European Urology, vol. 23, no. 3, pp. 394-399, 1993.

[18] D. R. Henly, D. M. Barrett, T. L. Weiland, M. K. O'Connor, A. A. Malizia, and A. J. Wein, "Particulate silicone for use in periurethral injections: local tissue effects and search for migration," The Journal of Urology, vol. 153, no. 6, pp. 20392043, 1995.

[19] E. C. Janowsky, L. L. Kupper, and B. S. Hulka, "Meta-analyses of the relation between silicone breast implants and the risk of connective-tissue diseases," The New England Journal of Medicine, vol. 342, no. 11, pp. 781-790, 2000.

[20] L. Cooperman and D. Michaeli, "The immunogenicity of injectable collagen-II: a retrospective review of seventy-two tested and treated patients," Journal of the American Academy of Dermatology, vol. 10, no. 4, pp. 647-651, 1984.

[21] Å. Stenberg, E. Larsson, A. Lindholm, B. Ronneus, A. Stenberg, and G. Läckgren, "Injectable dextranomer-based implant: histopathology, volume changes and DNA-analysis," Scandinavian Journal of Urology and Nephrology, vol. 33, no. 6, pp. 355-361, 1999.

[22] A. Stenberg, E. Larsson, and G. Läckgren, "Endoscopic treatment with dextranomer-hyaluronic acid for vesicoureteral reflux: histological findings," The Journal of Urology, vol. 169, no. 3, pp. 1109-1113, 2003.

[23] L. P. McMann, H. C. Scherz, and A. J. Kirsch, "Longterm preservation of dextranomer/hyaluronic acid copolymer implants after endoscopic treatment of vesicoureteral reflux in children: a sonographic volumetric analysis," The Journal of Urology, vol. 177, no. 1, pp. 316-320, 2007.

[24] J. A. Molitierno, H. C. Scherz, and A. J. Kirsch, "Endoscopic treatment of vesicoureteral reflux using dextranomer hyaluronic acid copolymer," Journal of Pediatric Urology. In press.

[25] N. Capozza, A. Lais, E. Matarazzo, S. Nappo, M. Patricolo, and P. Caione, "Influence of voiding dysfunction on the outcome of endoscopic treatment for vesicoureteral reflux," The Journal of Urology, vol. 168, no. 4, supplement 1, pp. 1695-1698, 2002.

[26] J. M. Elmore, H. C. Scherz, and A. J. Kirsch, "Dextranomer/hyaluronic acid for vesicoureteral reflux: success rates after initial treatment failure," The Journal of Urology, vol. 175, no. 2, pp. 712-715, 2006.

[27] J. S. Elder, M. Diaz, A. A. Caldamone, et al., "Endoscopic therapy for vesicoureteral reflux: a meta-analysis-I: reflux resolution and urinary tract infection," The Journal of Urology, vol. 175, no. 2, pp. 716-722, 2006.

[28] G. Läckgren, N. Wåhlin, E. Sköldenberg, and A. Stenberg, "Long-term followup of children treated with dextranomer/hyaluronic acid copolymer for vesicoureteral reflux," The Journal of Urology, vol. 166, no. 5, pp. 1887-1892, 2001.
[29] J. B. Campbell, T. S. Lendvay, M. C. Risk, et al., "Endoscopic treatment of symptomatic refluxing renal transplant ureteroneocystostomies in children," in Proceedings of the Annual Meeting of the American Urological Association, Anaheim, Calif, USA, May 2007.

[30] J. A. Molitierno Jr., H. C. Scherz, and A. J. Kirsch, "Endoscopic injection of dextranomer hyaluronic acid copolymer for the treatment of vesicoureteral reflux in duplex ureters," Journal of Pediatric Urology. In press.

[31] W. H. Cerwinka, H. C. Scherz, and A. J. Kirsch, "Endoscopic treatment of vesicoureteral reflux associated with paraureteral diverticula in children," The Journal of Urology, vol. 178, no. 4, pp. 1469-1473, 2007.

[32] B. Chertin, N. Mohanan, A. Farkas, and P. Puri, "Endoscopic treatment of vesicoureteral reflux associated with ureterocele," The Journal of Urology, vol. 178, no. 4, supplement 1, pp. 15941597, 2007.

[33] N. Capozza, A. Lais, S. Nappo, and P. Caione, "The role of endoscopic treatment of vesicoureteral reflux: a 17-year experience," The Journal of Urology, vol. 172, no. 4, supplement 1, pp. 1626-1629, 2004.

[34] A. J. Kirsch, J. M. Elmore, J. Molitierno, and H. C. Scherz, "The double HIT methodology for the endoscopic correction of vesicoureteral reflux," in Proceedings of the Annual Meeting of the American Urological Association, Atlanta, Ga, USA, May 2006.

[35] J.-W. van Capelle, T. de Haan, W. El Sayed, and A. Azmy, "The long-term outcome of the endoscopic subureteric implantation of polydimethylsiloxane for treating vesico-ureteric reflux in children: a retrospective analysis of the first 195 consecutive patients in two European centres," BJU International, vol. 94, no. 9, pp. 1348-1351, 2004.

[36] A.-M. Kajbafzadeh, Z. Habibi, and P. Tajik, "Endoscopic subureteral urocol injection for the treatment of vesicoureteral reflux," The Journal of Urology, vol. 175, no. 4, pp. 1480-1483, 2006.

[37] P. Puri, M. Pirker, N. Mohanan, M. Dawrant, L. Dass, and E. Colhoun, "Subureteral dextranomer/hyaluronic acid injection as first line treatment in the management of high grade vesicoureteral reflux," The Journal of Urology, vol. 176, no. 4, supplement 1, pp. 1856-1860, 2006.

[38] A. J. Lorenzo, J. L. Pippi Salle, U. Barroso, et al., "What are the most powerful determinants of endoscopic vesicoureteral reflux correction? Multivariate analysis of a single institution experience during 6 years," The Journal of Urology, vol. 176, no. 4, supplement 1, pp. 1851-1855, 2006.

[39] K. J. Pinto, J. Pugach, and J. Saalfield, "Lack of usefulness of positioned instillation of contrast cystogram after injection of dextranomer/hyaluronic acid," The Journal of Urology, vol. 176, no. 6, pp. 2654-2656, 2006.

[40] M. T. Lavelle, M. J. Conlin, and S. J. Skoog, "Subureteral injection of Deflux for correction of reflux: analysis of factors predicting success," Urology, vol. 65, no. 3, pp. 564-567, 2005.

[41] S. Yucel, A. Gupta, and W. Snodgrass, "Multivariate analysis of factors predicting success with dextranomer/hyaluronic acid injection for vesicoureteral reflux," The Journal of Urology, vol. 177, no. 4, pp. 1505-1509, 2007.

[42] J. C. Routh, Y. Reinberg, R. A. Ashley, et al., "Multivariate comparison of the efficacy of intraureteral versus subtrigonal techniques of dextranomer/hyaluronic acid injection," The Journal of Urology, vol. 178, no. 4, supplement 1, pp. 17021706, 2007. 
[43] G. Kobelt, D. A. Canning, T. W. Hensle, and G. Läckgren, "The cost-effectiveness of endoscopic injection of dextranomer/hyaluronic acid copolymer for vesicoureteral reflux," The Journal of Urology, vol. 169, no. 4, pp. 1480-1484, 2003.

[44] R. M. Benoit, P. B. Peele, and S. G. Docimo, "The costeffectiveness of dextranomer/hyaluronic acid copolymer for the management of vesicoureteral reflux. 1: substitution for surgical management," The Journal of Urology, vol. 176, no. 4, pp. 1588-1592, 2006.

[45] D. R. Vandersteen, J. C. Routh, A. J. Kirsch, et al., "Postoperative ureteral obstruction after subureteral injection of dextranomer/hyaluronic acid copolymer," The Journal of Urology, vol. 176, no. 4, pp. 1593-1595, 2006.

[46] C. S. Cooper, B. I. Chung, A. J. Kirsch, D. A. Canning, and H. M. Snyder III, "The outcome of stopping prophylactic antibiotics in older children with vesicoureteral reflux," The Journal of Urology, vol. 163, no. 1, pp. 269-273, 2000. 


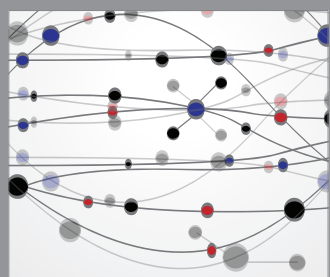

The Scientific World Journal
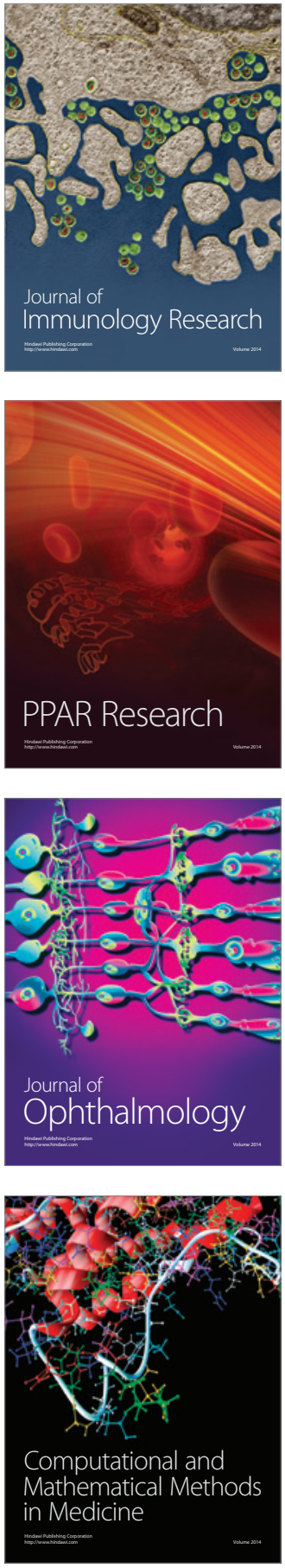

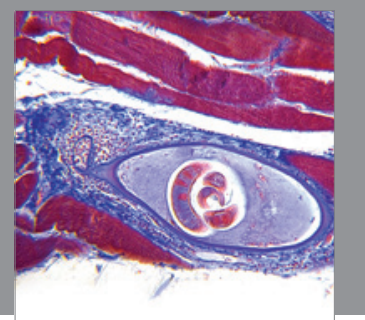

Gastroenterology

Research and Practice
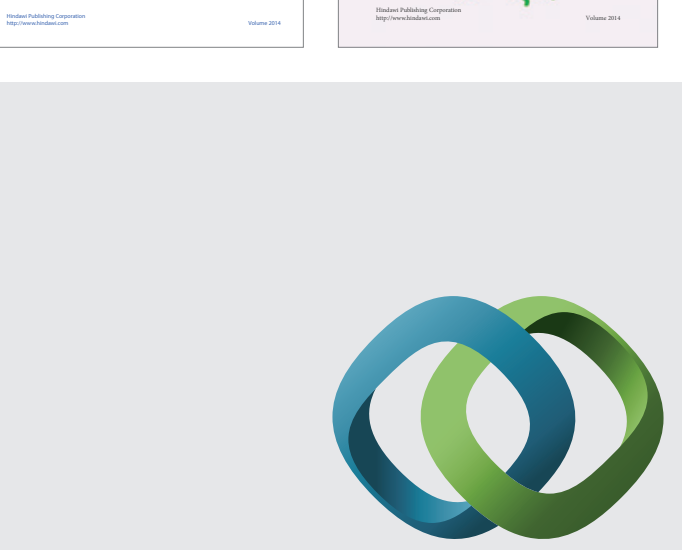

\section{Hindawi}

Submit your manuscripts at

http://www.hindawi.com
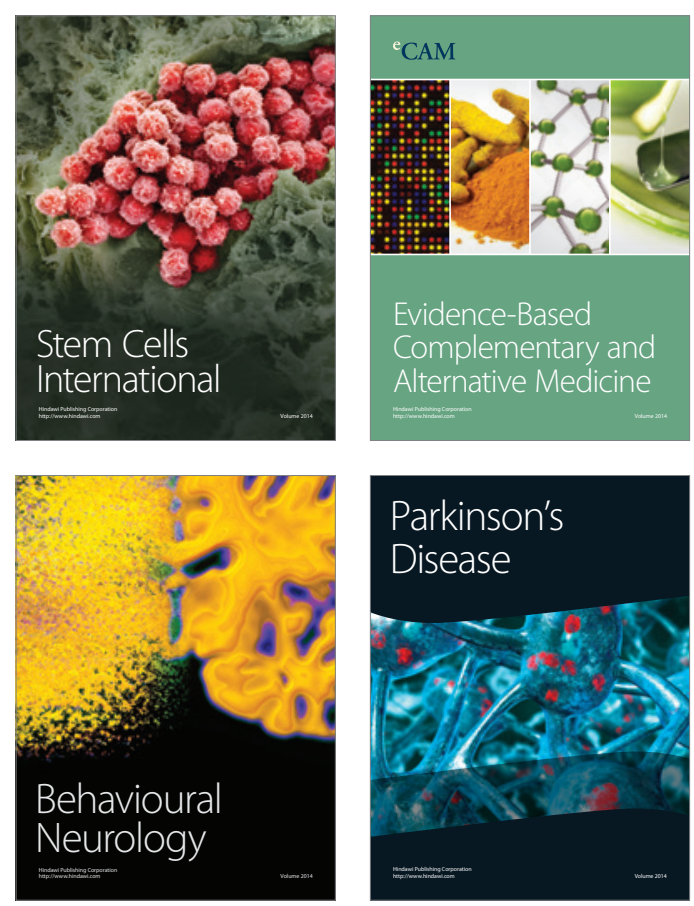

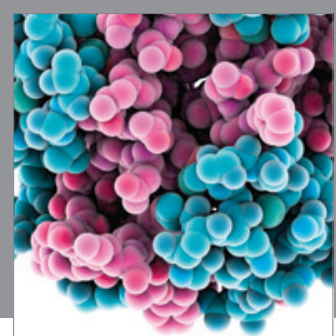

Journal of
Diabetes Research

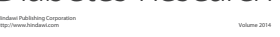

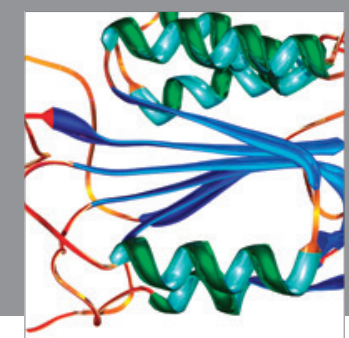

Disease Markers
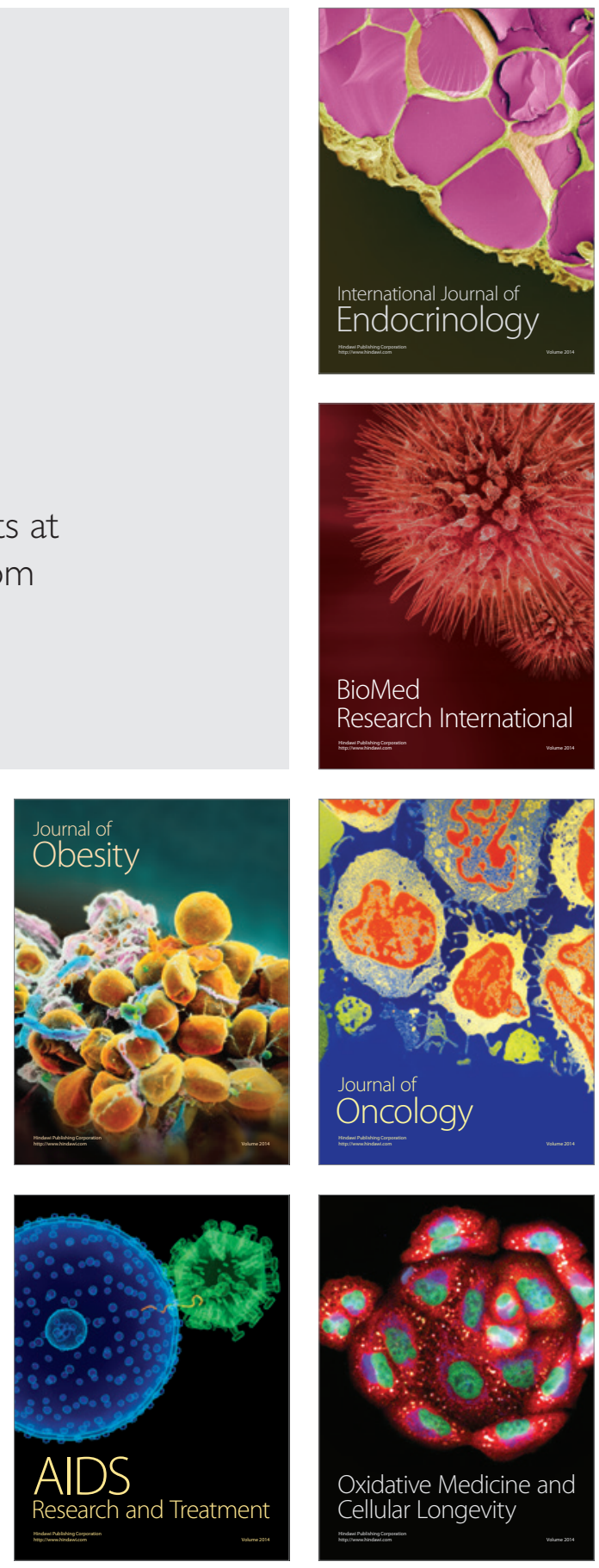